\title{
Transsulfuration is an active pathway for cysteine biosynthesis in Trypanosoma rangeli
}

Ibeth Romero ${ }^{1 *}$, Jair Téllez ${ }^{1 \dagger}$, Lais Eiko Yamanaka', Mario Steindel', Alvaro José Romanha ${ }^{1,2}$ and Edmundo Carlos Grisard ${ }^{1 *}$

\begin{abstract}
Background: Cysteine, a sulfur-containing amino acid, plays an important role in a variety of cellular functions such as protein biosynthesis, methylation, and polyamine and glutathione syntheses. In trypanosomatids, glutathione is conjugated with spermidine to form the specific antioxidant thiol trypanothione $\left(\mathrm{T}[\mathrm{SH}]_{2}\right)$ that plays a central role in maintaining intracellular redox homeostasis and providing defence against oxidative stress.

Methods: We cloned and characterised genes coding for a cystathionine $\beta$-synthase (C $\beta S$ ) and cysteine synthase (CS), key enzymes of the transsulfuration and assimilatory pathways, respectively, from the hemoflagellate protozoan parasite Trypanosoma rangeli.

Results: Our results show that T. rangeli $C \beta S(\operatorname{TrC} \beta S)$, similar to its homologs in $T$. cruzi, contains the catalytic domain essential for enzymatic activity. Unlike the enzymes in bacteria, plants, and other parasites, T. rangeli CS lacks two of the four lysine residues $\left(\right.$ Lys $^{26}$ and Lys ${ }^{184}$ ) required for activity. Enzymatic studies using T. rangeli extracts confirmed the absence of CS activity but confirmed the expression of an active C $B S$. Moreover, C $\beta S$ biochemical assays revealed that the T. rangeli C $\beta S$ enzyme also has serine sulfhydrylase activity.

Conclusion: These findings demonstrate that the RTS pathway is active in T. rangeli, suggesting that this may be the only pathway for cysteine biosynthesis in this parasite. In this sense, the RTS pathway appears to have an important functional role during the insect stage of the life cycle of this protozoan parasite.
\end{abstract}

Keywords: Cysteine biosynthesis, Cystathionine $\beta$-synthase, Cysteine synthase, T. rangeli, Thiol metabolism, Antioxidant defence

\section{Background}

L-cysteine, a sulfur-containing amino acid, is indispensable for the survival of virtually all living organisms, from bacteria to higher eukaryotes. This amino acid is implicated in several processes, including the stability, structure, regulation of catalytic activity, and posttranslational modification of various proteins [1]. Due to the ability of its thiol group to undergo redox reactions, L-cysteine forms the basic building block of all thiol antioxidants, acting as a direct antioxidant and also as a precursor for the biosynthesis of glutathione, trypanothione, or ovothiol [2]. In addition, cysteine is also essential for the synthesis of biomolecules, including

\footnotetext{
*Correspondence: ibicris@gmail.com; edmundo.grisard@ufsc.br ${ }^{\dagger}$ Equal contributors

'Laboratórios de Protozoologia e de Bioinformática, Departamento de Microbiologia, Imunologia e Parasitologia, Centro de Ciências Biológicas, Universidade Federal de Santa Catarina, Florianópolis, SC 88040-970, Brasil Full list of author information is available at the end of the article
}

coenzyme A, hypotaurine, taurine, and ubiquitous ironsulphur (Fe-S) clusters, which are involved in electron transfer, redox regulation, nitrogen fixation, and regulatory process sensing $[3,4]$.

Two different routes for cysteine biosynthesis have been described: reverse-transsulfuration (RTS) and de novo or assimilatory pathways. RTS has been demonstrated in fungi and mammals and includes the complete process leading to cysteine from methionine via the intermediary formation of cystathionine [5]. These reactions are catalysed by two enzymes, $C \beta S$ (cystathionine $\beta$-synthase), which synthesizes cystathionine from homocysteine and serine, and CGL (cystathionine $\gamma$-lyase), which forms cysteine from cystathionine [6]. The de novo pathway is also catalysed by two steps starting with serine acetyltransferase (SAT) to form O-acetylserine (OAS) from L-serine and acetyl-coenzyme A. Subsequently, OAS

\section{Ciomed Central}

(c) 2014 Romero et al.; licensee BioMed Central Ltd. This is an Open Access article distributed under the terms of the Creative Commons Attribution License (http://creativecommons.org/licenses/by/2.0), which permits unrestricted use, distribution, and reproduction in any medium, provided the original work is properly credited. The Creative Commons Public Domain Dedication waiver (http://creativecommons.org/publicdomain/zero/1.0/) applies to the data made available in this article, unless otherwise stated. 
reacts with sulfide to produce cysteine in an alanyltransfer reaction by cysteine synthase (CS) [7]. This de novo pathway for cysteine biosynthesis is found in plants, bacteria, and some protozoa, such as Entamoeba histolytica, Entamoeba dispar [8], Leishmania major [9], and Leishmania donovani [10], but is absent in mammals [11]. Both C $\beta S$ and CS are PLP-dependent enzymes that are evolutionary-related and in most cases some CS activity has been demonstrated for the $C \beta S$ enzymes described to date [12].

It is well established that the antioxidant defence system plays a key role in the host-parasite interaction for intracellular pathogenic trypanosomatids such as $T$. cruzi and Leishmania spp., promoting the protection of the parasite against macrophage-derived oxygen and nitrogenreactive species [13,14]. Among trypanosomatids, the mammalian-infective and non-pathogenic Trypanosoma rangeli is of growing interest because its intracellular life stage within mammalian hosts is still unknown and its sympatric occurrence with T. cruzi [15].

Because $T$. rangeli is required for a response to a variety of oxidative stresses in both mammalian and invertebrate hosts, the present study characterised genes encoding key enzymes of cysteine biosynthesis, a crucial precursor of trypanothione.

\section{Methods}

\section{Parasites and culture}

Epimastigotes of T. rangeli Choachí strain and T. cruzi Y strain were grown at $26.5^{\circ} \mathrm{C}$ in liver infusion tryptose medium (LIT) supplemented with $10 \%$ heat-inactivated fetal bovine serum (FBS), 100 units/mL penicillin, and $100 \mu \mathrm{g} / \mathrm{mL}$ streptomycin by weekly passaging [16]. Parasites were harvested at the late log phase for DNA or protein extraction as well as for thiol profiling and in vitro oxidative and nitrosative stress testing. Trypomastigotes of $T$. rangeli were obtained in vitro under conditions previously described [17].

T. cruzi culture-derived trypomastigotes and amastigotes were obtained from THP-1 differentiated macrophage-like cells (ATCC) infected with Y strain metacyclic trypomastigotes [18]. Briefly, THP-1 cells (ATCC) were cultured in RPMI 1640 medium supplemented with $10 \%$ FBS at $37^{\circ} \mathrm{C}$ in a $5 \% \mathrm{CO}_{2}$ atmosphere and transformed to adherent macrophages using phorbol myristate acetate $(50 \mathrm{ng} / \mathrm{mL})$ for $72 \mathrm{~h}$ at $37^{\circ} \mathrm{C}$ and $5 \% \mathrm{CO}_{2}$ prior to experiments. THP-1 macrophage-like cells were infected with $T$. cruzi trypomastigotes for $2 \mathrm{~h}$ at a 3:1 parasitecell ratio and then washed to remove the extracellular parasites. After $72 \mathrm{~h}$ at $37^{\circ} \mathrm{C}$ under $5 \% \mathrm{CO}_{2}$, the trypomastigotes were collected from the culture supernatant, centrifuged at $600 \times g$ for $30 \mathrm{~min}$, and then left under the same conditions for $3 \mathrm{~h}$ to separate the trypomastigotes from the amastigotes and cellular debris. The supernatant containing the trypomastigotes was used for protein extraction.

\section{Identification of $T$. rangeli $\mathrm{C} \beta \mathrm{S}$ and $\mathrm{CS}$}

Both the $T$. rangeli genome and transcriptome databases (http://www.rangeli.lncc.br) [19] were searched using the TBLASTN algorithm with the protein sequences of cystathionine $\beta$-synthase $(C \beta S)$ and cysteine synthase (CS) from bacteria, yeast, plants, and parasitic protozoa as queries to identify putative $T$. rangeli proteins involved in transsulfuration and assimilatory pathways. Other coding sequences for potential enzymes comprising the two biosynthetic pathways were also searched in the genome and transcriptome databases. T. rangeli genomic DNA (gDNA) was isolated by the phenol-chloroform method following a standard protocol [20]. The open reading frames (ORFs) of the $C \beta S$ and $C S$ genes were amplified by PCR using gene-specific primers: CBTrXhoI (5'-CTC GAG ACC ATG GCT CAA ACC CAC-3') and CBTrBamHI (5'-GGA TCC GCG CAC CTG CTT TTT ATC C-3') for $C \beta S$ and CSTrNdeI (5'CAT ATG GAA GCT CTC ATC GGG G-3') and CSTrXhol (5' - CTC GAG CCA GCA CCA CGG GAA GC-3') for CS. Sites for restriction enzymes (included in the primer name; bolded nucleotides) were included to allow cloning. All PCR assays were carried out using a Mastercycler ${ }^{\bullet}$ Gradient (Eppendorf, Hamburg) for $30 \mathrm{cy}-$ cles of denaturation $\left(94^{\circ} \mathrm{C}, 1 \mathrm{~min}\right)$, annealing $\left(60^{\circ} \mathrm{C}\right.$, $45 \mathrm{sec}$ ), and extension $\left(72^{\circ} \mathrm{C}, 1 \mathrm{~min}\right)$, followed by a final extension step $\left(72^{\circ} \mathrm{C}\right)$ for $5 \mathrm{~min}$. The PCR products were cloned into the pGEM-T-Easy vector (Promega), and the resulting constructs were verified by sequencing using a Megabace $1000^{\circ}$ DNA Analysis System with the DYEnamic ET terminators kit (GE Healthcare) according to the manufacturer's conditions. Both DNA strands were sequenced for each clone obtained; after analysis using the Phred/Phrap/Consed package [21], only high-quality DNA sequences (Phred $\geq 20$ ) were compared with the public databases using the GenBank BLAST algorithm.

\section{Protein expression and purification}

The inserts corresponding to the $C \beta S$ and $C S$ ORFs cloned into pGEM-T-Easy (Promega) were excised and subcloned into the pET14b expression vector (Novagen) pre-digested with the appropriate restriction enzymes (included in the PCR primers). The resulting plasmids containing the $C \beta S$ and $C S$ genes were named pET14$\operatorname{TrC} \beta S$ and pET14-TrCS, respectively, and re-sequenced for confirmation as described above.

The pET14-TrC $\beta$ S plasmid was used to transform $E$. coli BL21 (DE3) for recombinant protein expression. Pre-inoculum was grown overnight in LB (LuriaBertani) broth supplemented with $100 \mu \mathrm{g} / \mathrm{mL}$ ampicillin at $37^{\circ} \mathrm{C}$ and then used to inoculate fresh LB until an 
O.D.600 of 0.6 was reached. The expression of recombinant $C \beta S(r \operatorname{Tr} C \beta S)$ was induced with $1 \mathrm{mM}$ isopropyl $\beta$ $\mathrm{D}$-thiogalactopyranoside (IPTG) for $2 \mathrm{~h}$ at $37^{\circ} \mathrm{C}$. The cells were harvested and resuspended in $5 \mathrm{~mL}$ of buffer A [50 mM sodium phosphate, $0.3 \mathrm{M} \mathrm{NaCl}, \mathrm{pH} 8.0$, and $25 \mu \mathrm{M}$ pyridoxal phosphate (PLP)] containing $5 \mathrm{mM}$ imidazole and then disrupted by sonication. The soluble and insoluble fractions were recovered by centrifugation at $16,000 \times g$ for $30 \mathrm{~min}$ at $4^{\circ} \mathrm{C}$ [9]. $\mathrm{rTrC} \beta S$ was purified from insoluble fractions by affinity chromatography on a $\mathrm{Ni}^{2+}$-nitrilotriacetic (NTA) column (Qiagen) following standard procedures. Briefly, the insoluble fraction was resuspended in a buffer containing $8 \mathrm{M}$ urea, $10 \mathrm{mM}$ Tris, and $100 \mathrm{mM} \mathrm{NaH}{ }_{2} \mathrm{PO}_{4}, \mathrm{pH}$ 8.0, and incubated for $1 \mathrm{~h}$ at $65^{\circ} \mathrm{C}$ to dissolve the inclusion bodies and then centrifuged $\left(10,000 \times g\right.$ for $30 \mathrm{~min}$ at $\left.4^{\circ} \mathrm{C}\right)$. The supernatants were then applied to the $\mathrm{Ni}^{2+}$-nitrilotriacetic (NTA) resin (Qiagen) pre-equilibrated with the same buffer and incubated for $1 \mathrm{~h}$ at $4^{\circ} \mathrm{C}$ under continuous agitation. The resin was washed three times using washing buffer $\left(100 \mathrm{mM} \mathrm{NaH} \mathrm{PO}_{4}, 100 \mathrm{mM}\right.$ Tris/ $\mathrm{HCl}$, and $8 \mathrm{M}$ urea, $\mathrm{pH}$ 6.3), and $\mathrm{rTrC} \beta \mathrm{S}$ elution was carried out using an appropriate buffer (100 mM NaH $\mathrm{PO}_{4}$, $100 \mathrm{mM}$ Tris $/ \mathrm{HCl}$, and $8 \mathrm{M}$ urea, $\mathrm{pH} 4.5)$. The eluted proteins were dialysed using $50 \mathrm{mM} \mathrm{NaH} \mathrm{PO}_{4} \mathrm{pH} 7.4$, $300 \mathrm{mM} \mathrm{NaCl}$ and $150 \mathrm{mM}$ imidazole overnight at $4^{\circ} \mathrm{C}$. The purity of the recombinant protein was then assessed by SDS-PAGE, and its concentration was determined by the Bradford method (Bio-Rad) using BSA as a standard. The protein was stored at $-20^{\circ} \mathrm{C}$.

To obtain recombinant CS ( $\mathrm{rTrCS})$, different approaches were assessed. pET14-TrCS was introduced into E. coli BL21 (DE3), BL21 (DE3)pLysS, and Rosetta strain, and expression was induced using different IPTG concentrations $(0.2,0.5$, or $1.0 \mathrm{mM})$ and temperatures $\left(15^{\circ} \mathrm{C}, 25^{\circ} \mathrm{C}\right.$, or $\left.37^{\circ} \mathrm{C}\right)$. Despite the number of experimental conditions tested, it was not possible to obtain recombinant $\mathrm{TrCS}$.

\section{Production of $\alpha-r \operatorname{TrC} \beta S$ mouse polyclonal antibodies}

Approximately $50 \mu \mathrm{g}$ of purified $\mathrm{rTrC} \beta \mathrm{S}(44 \mathrm{kDa})$ was subcutaneously inoculated into Balb/C mice using Alu-Gel (Serva) as an adjuvant. Each mouse received four consecutive inoculations at 12-day intervals, with monitoring for an antibody response using enzyme-linked immunosorbent assay (ELISA) with rTrC $\beta S$ as the antigen.

\section{Comparative analysis of $\mathrm{C} \beta \mathrm{S}$ expression by $T$. rangeli and T. cruzi}

Quantification of C $\beta S$ expression was performed using soluble protein fractions from T. rangeli and T. cruzi. A total of $1 \times 10^{8}$ epimastigotes or trypomastigotes were washed once with D-PBS and lysed by repeated aspiration in ice-cold lysis buffer (0.25 M sucrose, $0.25 \%$ Triton X-100, and $10 \mathrm{mM}$ EDTA) containing a protease inhibitor cocktail (Sigma-Aldrich). Cellular debris was removed by centrifugation at $12,000 \times g$ for $20 \mathrm{~min}$ at $4^{\circ} \mathrm{C}$ [22]. The protein concentrations in the extract were determined by the Bradford method (Bio-Rad) using BSA as a standard and stored at $-20^{\circ} \mathrm{C}$.

Soluble protein extracts $(30 \mu \mathrm{g})$ of the different life cycle stages of $T$. rangeli and $T$. cruzi were fractionated on 12\% SDS-PAGE and electroblotted onto nitrocellulose membranes (GE Healthcare) in an appropriate buffer (25 mM Tris; $192 \mathrm{mM}$ glycine; 20\% v/v methanol, $\mathrm{pH}$ 8.3). The membranes were then blocked with $5 \%$ non-fat milk in blotting buffer $(25 \mathrm{mM}$ Tris- $\mathrm{HCl}$ $\mathrm{pH} 7.4,150 \mathrm{mM} \mathrm{NaCl}$, and $0.1 \%$ Tween-20) overnight at $4^{\circ} \mathrm{C}$ [23]. After blocking, the membranes were incubated for $1 \mathrm{~h}$ with an anti-rTrC $\beta S$ mouse polyclonal antiserum $(1: 4,000)$ or anti- $\alpha$ tubulin monoclonal antibody $(1: 10,000)$ used as a loading control. After washing, the membranes were incubated with anti-mouse IgG conjugated to horseradish peroxidase $(1: 10,000)$, followed by washing and detection on radiographic films using an ECL kit (Pierce) according to the manufacturer's recommendations. The western blots were digitally analysed using the software package Image J 1.463r, subtracting the background of each blot prior to measuring the intensity of specific bands. Integrated densities for each band were determined for each protein of interest and its corresponding loading control. The ratio of the band intensity of the protein of interest versus the band intensity of the corresponding loading control was used as the relative protein expression level and allowed the comparison with other samples.

\section{Enzymatic assays for C $\beta$ S and CS activities Cystathionine $\beta$-synthase}

The assay method described by Walker and Barret was used [24]. Briefly, the reaction mixture contained $70 \mu \mathrm{mol}$ Tris-HCl buffer ( $\mathrm{pH} 8.4$ ), $0.4 \mathrm{mM}$ PLP, and $1.5 \mu \mathrm{g} / \mu \mathrm{L}$ of total protein extract from parasites or $0.1 \mu \mathrm{g} / \mu \mathrm{L}$ of $\mathrm{rTrC} \beta S$ (as a positive control) in a final volume of $100 \mu \mathrm{L}$. In the case of the protein extract, the mixture also contained $0.1 \mathrm{mM} \mathrm{CuSO}_{4}$ to inhibit cystathionase activity. All components were equilibrated for $2 \mathrm{~min}$ at $37^{\circ} \mathrm{C}$, and the reaction was initiated by the addition of $40 \mathrm{mM}$ D,L-homocysteine and $20 \mathrm{mM}$ L-serine. The reaction was stopped $45 \mathrm{~min}$ later by the addition of $100 \mu \mathrm{L} 50 \%(\mathrm{w} / \mathrm{v})$ trichloroacetic acid. The precipitated protein was removed by centrifugation at $12,000 \times g$ for $5 \mathrm{~min}$, and the amount of cystathionine was determined by adding $1 \mathrm{~mL}$ of acid-ninhydrin reagent ( $1 \mathrm{~g}$ ninhydrin dissolved in $100 \mathrm{~mL}$ concentrated acetic acid and $1 / 3$ volume of phosphoric acid) to $100 \mu \mathrm{L}$ of the assay supernatant fraction. The mixture was then boiled for $5 \mathrm{~min}$, cooled for $2 \mathrm{~min}$ on ice, and incubated for $20 \mathrm{~min}$ at room temperature $\left(25^{\circ} \mathrm{C}\right)$ for 


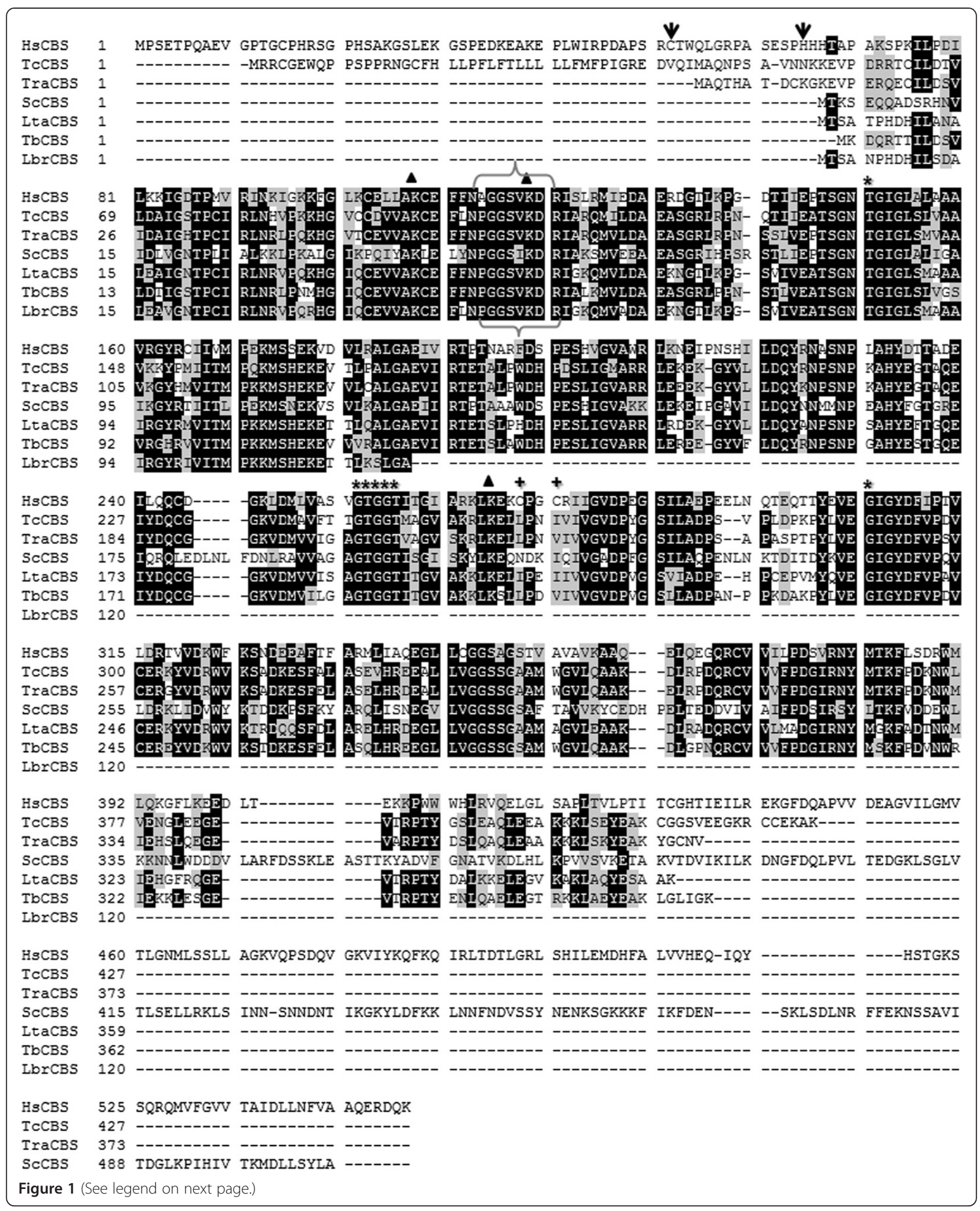


(See figure on previous page.)

Figure 1 Multiple alignment of deduced amino acid sequences of $C \beta S$ from $T$. rangeli $(\operatorname{TrC} \beta S)$ and other representative organisms. The identity (black background) and conservation (grey background) of the amino acid residues are shown. Brackets indicate the consensus amino acid residues of the putative pyridoxal phosphate-binding motif (PXXSVKDR), and other motifs vital for C $\beta S$ activity are indicated with asterisks $\left(^{*}\right)$. The oxido-reductase motif of $\mathrm{HSC} \beta S$ is highlighted with $(+)$. The lysine residues required for CS catalytic activity are marked with triangles. The positions of the heme-binding residues within the heme domain of the human C $\beta S$ enzyme $\left(C y s^{52}\right.$ and His $\left.^{65}\right)$ are marked with $(\downarrow)$.

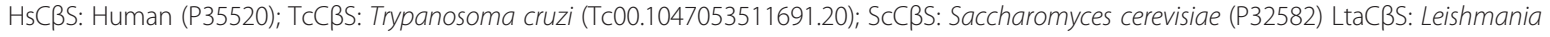
tarentolae (LtaP17.0270); TbCßS: Trypanosoma brucei (Tb11.02.5400); LbrCßS: Leishmania braziliensis (LbrM.17.0230).

colour development. The absorbance was measured at $455 \mathrm{~nm}$. Each enzymatic assay was performed including negative controls (all reagent components without enzyme or without substrate). A standard curve was prepared using $0-3 \mu \mathrm{mol}$ of cystathionine dissolved in acidninhydrin reagent and treated as described above to quantify the amount of cystathionine formed [25].

\section{Cysteine synthase}

The CS activity in the total protein extracts from parasites $(1.5 \mu \mathrm{g} / \mu \mathrm{L})$ or bacteria (positive control) was determined by measuring cysteine production at $37^{\circ} \mathrm{C}$ in a $500 \mu \mathrm{L}$ reaction containing $200 \mathrm{mM}$ potassium phosphate buffer ( $\mathrm{pH}$ 7.5), $10 \mathrm{mM}$ DTT, $0.2 \mathrm{mM}$ PLP, $6.5 \mathrm{mM} O$-acetylserine (OAS), and $4 \mathrm{mM}$ sodium sulfide $\left(\mathrm{Na}_{2} \mathrm{~S}\right)$. All the components except sodium sulfide were pre-incubated for $5 \mathrm{~min}$ at $37^{\circ} \mathrm{C}$; the reaction was initiated by the addition of sodium sulfide and incubated for another $30 \mathrm{~min}$ and then stopped using $50 \mu \mathrm{L}$ of $20 \%$ trichloroacetic acid $(\mathrm{w} / \mathrm{v})$. The mixture was centrifuged for $5 \mathrm{~min}$ at $12,000 \times g$, and the supernatant was used for cysteine analysis, as previously described with some modifications [26]. Briefly, an aliquot $(500 \mu \mathrm{L})$ of the supernatant was added to $500 \mu \mathrm{L}$ of ninhydrin reagent (250 mg ninhydrin dissolved in $10 \mathrm{~mL}$ concentrated acetic acid: concentrated $\mathrm{HCl}, 60 \sim 40 \mathrm{v} / \mathrm{v})$. The mixture was boiled for $10 \mathrm{~min}$ and immediately cooled on ice before the addition of $500 \mu \mathrm{L}$ of $95 \%(\mathrm{v} / \mathrm{v})$ ethanol. The amount of cysteine formed was determined by measuring the absorbance of the reaction mixture at $560 \mathrm{~nm}$ [27]. Each enzymatic assay was performed including negative controls (all reagent components without enzyme or without substrate). A standard curve was prepared with L-cysteine $(0-1 \mu \mathrm{mol})$ dissolved in ninhydrin reagent and treated as described above to quantify the amount of cysteine formed. The serine sulfhydrylase activity of CS was determined in the same way as described for the CS assay above, except that $6.5 \mathrm{mM}$ serine was used instead of OAS.

\section{Cellular thiol contents}

The total thiol content of T. rangeli and T. cruzi epimastigotes was determined using deproteinised parasite extracts prepared as formerly described [28]. Epimastigotes in the exponential phase $\left(1 \times 10^{8}\right.$ parasites $\left./ \mathrm{mL}\right)$ were harvested, washed with D-PBS, and suspended in $0.6 \mathrm{~mL}$ of $25 \%$ trichloroacetic acid. After $10 \mathrm{~min}$ on ice, the denatured proteins and cell debris were removed by centrifugation at $13,000 \times g$ for $10 \mathrm{~min}$ at $4^{\circ} \mathrm{C}$. The thiol content of the supernatant solution was determined by Ellman's method [29] using $0.6 \mathrm{mM}$ 5,5'-dithio-bis(2nitrobenzoic acid) (DTNB) in $0.2 \mathrm{M}$ sodium phosphate buffer ( $\mathrm{pH}$ 8.0). The concentration of DTNB derivatives of thiols was estimated spectrophotometrically at $412 \mathrm{~nm}$. Calibration curves were performed with known amounts of cysteine.

\section{Epimastigote susceptibility to oxidative and nitrosative stress in vitro}

Parasite susceptibility to oxidative or nitrosative stress was assessed using Alamar blue (AB) assays, as described elsewhere $[22,30]$ with minor modifications. Briefly, $5 \times 10^{5}$ $T$. rangeli and $T$. cruzi epimastigotes were incubated for $48 \mathrm{~h}$ with $100 \mu \mathrm{L}$ parasite culture in quadruplicate in 96-well plates. Aliquots of $100 \mu \mathrm{L}$ of $30 \%$ hydrogen peroxide (Sigma-Aldrich) or S-nitroso-N-acetylpenicillamine (SNAP, Molecular Probes ${ }^{\oplus}$ Life Technologies) prepared at different dilutions (0-100-150-300-500-1000-1500 $\mu \mathrm{M}$ and $0-5-20-50-150-300-500-1000 \mu \mathrm{M}$, respectively) were added, as reported [22,31]. After incubation at $26^{\circ} \mathrm{C}$ for $24 \mathrm{~h}, 20 \mu \mathrm{L}$ of $\mathrm{AB}$ reagent (Invitrogen) was added to each well to assess parasite viability via fluorescence emission at $600 \mathrm{~nm}$. Data from treated and non-treated cultures were used to calculate the $\mathrm{IC}_{50}$ by a sigmoidal regression analysis (with variable slope) using GraphPad Prism v.5.0. Untreated control parasites and reagent blanks were included in each test plate.

\section{Statistical analysis}

All experiments were performed in triplicate, and the results are presented as the mean and the standard deviation (SD) or standard error of the mean (SEM). Normalised data were analysed by a one-way ANOVA followed by Bonferroni post-tests or Student's $t$-test, as indicated in the figure legends, using the software GraphPad Prism v.5.0.

\section{Ethical approval}

The procedures involving animals were previously approved by the UFSC Ethics Committee on Animal Use - CEUA (Reference number: 23080.025618/2009-81). 


\begin{tabular}{|c|c|c|}
\hline Tracs & 1 & 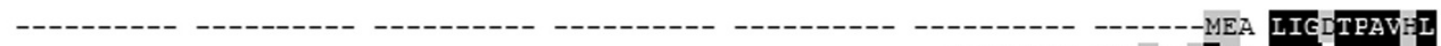 \\
\hline TcCs & 1 & 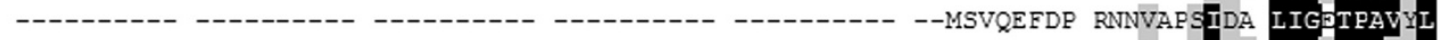 \\
\hline Lbrcs & 1 & $----M A A P F D T S$ \\
\hline $\operatorname{LmjCS}$ & 1 & $----M A A P F D K S$ \\
\hline EhCs & 1 & --- MEQIS- \\
\hline TvCs & 1 & ------- ---- \\
\hline StCs A & 1 & ------- \\
\hline StCS B & 1 & ---- \\
\hline Tracs & $\begin{array}{l}14 \\
29\end{array}$ & STISVRDREA YA \\
\hline Lbres & 28 & YDKAEKE GKIIRGKSIV V \\
\hline $\operatorname{Lmj} \mathrm{CS}$ & 28 & \\
\hline EhCs & 30 & SGNTGI $z$ \\
\hline TvCs & 19 & SGNTGI G \\
\hline StCs A & 21 & TGI \\
\hline StCs B & 17 & \\
\hline Tracs & 80 & YP $\mathrm{HHAAE}$ \\
\hline TcCs & 97 & IL TEAALGMKGA I \\
\hline Lbres & 96 & IL TEAALGMKGA M \\
\hline $\operatorname{Lmj} C S$ & 96 & IL TEAALGMKGA VTM \\
\hline EhCS & 102 & NKMIKE NP \\
\hline TvCs & 87 & $\mathrm{EIVKE}$ NP \\
\hline Stcs A & 86 & NPEIH EKTTGPEIRE \\
\hline Stcs B & 85 & DNPYZH YTTTGPEIWR \\
\hline Tracs & 155 & 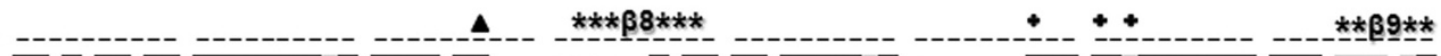 \\
\hline $\operatorname{TcCs}$ & 174 & QTAGVDDFV AGVGTGGIIT GVARYLK-S VGCGAII \\
\hline Lbrcs & 173 & KQQGIGAG $\mathbf{F}$ \\
\hline LmjCS & 173 & -K MGSHAR \\
\hline EhCs & 179 & IQGIGAG \\
\hline TvCS & 165 & KGHYIOG --------- ---LKSMEEA IVPAIYQADK \\
\hline StCs A & 164 & DTUGDVDVII SGVGIGGTLT GVIRYIKGTK GKTDLITVAV EPTLSPVIAQ ALAGEEIKPG FFYICGIGAG EIPGNLDLKL \\
\hline StCs B & 161 & QTSGRITHEV SSMGTHGIIT GVSRFIR--E QEKTVIIVGL QPPEGSSIFG --..---- -- IRRWPTE YMPGIFNASL \\
\hline Tracs & 155 & 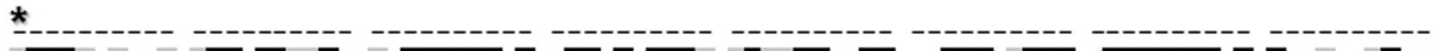 \\
\hline $\operatorname{TcCs}$ & 246 & IP RIDGIFCGES GGAVVYAALQ IRKRPEMIZK --TIVIVIPS YGERYLSTIL YSSI-KDEVS \\
\hline Lbres & 245 & gGK --TIVTVIPS FGERYLSTVL \\
\hline $\operatorname{Lmj} C S$ & 245 & EGK --TIVIIIPS FGERYLSTEL \\
\hline EhCs & 251 & GK --TIVIIVPS GGERYLSTDL YKIK-DEGTK \\
\hline TvCs & 230 & VAEKLESG-二 --VIVVLFAD FGERYYLSTRL FDTQ------ \\
\hline Stcs A & 244 & 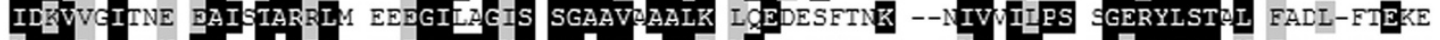 \\
\hline StCs B & 226 & 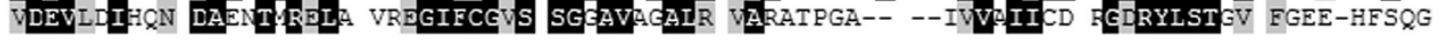 \\
\hline Tracs & 155 & --------- \\
\hline Tecs & 323 & ALKVLSAADI -- \\
\hline Lbres & 322 & SLPVVDASEL QD \\
\hline $\operatorname{Lmj} \mathrm{CS}$ & 322 & SLPVVDASEL QD \\
\hline EhCs & 328 & IQILDSLLNE -- \\
\hline TvCS & 299 & --------- - \\
\hline Stcs A & 321 & LQQ------- -- \\
\hline StCs B & 301 & AGI------- -- \\
\hline \multicolumn{3}{|c|}{$\begin{array}{l}\text { Figure } 2 \text { Multiple alignment of deduced amino acid sequences of CS from } T \text {. rangeli and other representative organisms. The identity } \\
\text { (black background) and conservation (grey background) of the amino acid residues are shown. Brackets indicate the consensus amino acid } \\
\text { residues of the putative pyridoxal phosphate-binding motif (PXXSVKDR); the substitute for the proline residue is marked with (•), and the lysine } \\
\text { residues required for cysteine synthase activity are indicated with triangles. The } \beta 8-\beta 9 \text { loop at the entrance of the active site is indicated with an } \\
\text { asterisk (*), and the positively charged residues involved in binding with SAT are indicated with (+). TraCS: Trypanosoma rangeli; TcCS: Trypanosoma cruz } \\
\text { (TC00.1047053507165.50); LbrCS: Leishmania braziliensis (LbrM.35.3820); LmjCS: Leishmania major (LmjF.36.3590); EhCS: Entamoeba histolytica; TVCS: } \\
\text { Trichomonas vaginalis (XP001325874); StCS A: Salmonella typhimurium CySK (POA1E4); StCS B: Salmonella typhimurium CysM (NP_456975). }\end{array}$} \\
\hline
\end{tabular}

\section{Results}

The $T$. rangeli genome contains genes encoding $C \beta S$ and CS enzymes

Using the nucleotide and protein sequences of $C \beta S$ and CS orthologs from plants, bacteria, yeast, and parasitic protozoa as queries, a search of $T$. rangeli genome and transcriptome databases allowed the identification of genes encoding $C \beta S$ and a partial gene sequence for $C S$. Additionally, the $T$. rangeli genome contains a single copy of the cystathionine $\gamma$-lyase (CGL) gene of the RTS 
pathway but lacks the genes encoding serine acetyltransferase (SAT) present in the de novo biosynthetic pathway of other trypanosomatids. The sequences for C $\beta S$ and CS were then back-searched using the SWISSPROT and NCBI databases, which confirmed the identity of both genes. These results suggest that, as in other trypanosomatids, $T$. rangeli possesses genes coding for the enzymes involved in these two cysteine biosynthetic routes: $\mathrm{C} \beta \mathrm{S}$ in the transsulfuration pathway and CS in the de novo biosynthesis pathway.

After cloning and sequencing, it was found that $T$. rangeli $C \beta S(\operatorname{Tr} C \beta S)$ predicts a protein of 373 amino acids $(44 \mathrm{kDa})$ that reveals high sequence identity with CBS from T. cruzi (84\%), T. brucei (78\%), and L. major (75\%) compared to human C $\beta S$ (50\%). Multiple sequence alignment confirmed that $\operatorname{TrC} \beta S$ contains three out of the four lysine residues (Lys ${ }^{53}$, Lys ${ }^{64}$, Lys ${ }^{213}$ ) required for CS activity; the consensus sequence for the putative cofactor pyridoxal phosphate-binding domain is highly conserved. rTrC $\beta S$, as well as $C \beta S$ from other trypanosomatids, differs from $H$. sapiens $\mathrm{C} \beta \mathrm{S}$ ( $\mathrm{HsC} \beta \mathrm{S})$ by lacking the haem-binding (redox sensor) and oxidoreductase motifs (Cys XX Cys) at the $\mathrm{N}$ - and C-termini, respectively (Figure 1 ).

The $T$. rangeli $\mathrm{CS}$ gene ( $\mathrm{TrCS}$ ) encodes a protein of 155 amino acids $(\sim 16.8 \mathrm{kDa})$ that is $53 \%$ identical to the T. cruzi ortholog but exhibits lower identity with $L$. major (46\%) and L. infantum (45\%). Although C $\beta S$ and CS are evolutionarily related enzymes, we found a low identity between $\operatorname{TrC} \beta S$ and $\operatorname{TrCS}(\leq 13 \%)$ when compared to the TrCS identity with the other orthologues from plants and bacteria ( 31-33\%). An analysis of the predicted amino acid sequences of TrCS revealed an amino acid change of $\mathrm{Pro}^{32} \rightarrow$ Ser within the putative pyridoxal phosphatebinding domain (PXXSVKDR). Unlike other CSs, TrCS has only two of the four lysine residues ( Lys $^{37}$, Lys ${ }^{53}$ ) shown to be important for the catalytic activity of the enzyme. Furthermore, TrCS does not have the canonical $\beta 8-\beta 9$ loop described in CS enzymes, which is important for access to the active site, and neither of the positively charged residues (Lys-His-Lys) involved in binding with serine acetyl-transferase (SAT) (Figure 2).

\section{Stage-specific expression of C $\beta S$ in $T$. rangeli}

The relative abundance of the $C \beta S$ protein was evaluated in $T$. rangeli epimastigote and trypomastigote forms by western blotting, showing no significant differences between the forms. The absence of $\operatorname{TrC} \beta S$ stage-specific expression contrasts with the homologous protein in T. cruzi (TcC $\beta S)$, for which the expression level of $C \beta S$ was found to be significantly increased in epimastigotes (Figure 3A, B).

\section{$\mathrm{C} \beta \mathrm{S}$ is active in $T$. rangeli}

The enzymatic studies on $T$. rangeli extracts showed that $\mathrm{C} \beta \mathrm{S}$ activity is detectable in both epimastigotes (0.13 $\left.\mu \mathrm{mol} \mathrm{min}^{-1} \mathrm{mg}^{-1}\right)$ and trypomastigotes $\left(0.079 \mu \mathrm{mol} \mathrm{min}{ }^{-1} \mathrm{mg}^{-1}\right.$ of protein) (Figure $\left.4 \mathrm{~A}\right)$, whereas $\mathrm{C} \beta \mathrm{S}$ activity was 1.9 times higher in the extracts from T. cruzi epimastigotes versus trypomastigotes. Conversely, CS activity was undetectable in the protein extracts from both $T$. rangeli forms (Figure $4 \mathrm{~B}$ ).

rTrC $\beta S$ showed C $\beta S$ activity of $2.2 \pm 0.2 \mu \mathrm{mol} \mathrm{min}^{-1}$ $\mathrm{mg}^{-1}$ of protein (Figure 4A), with a $k m$ of $1.702 \pm 0.11 \mathrm{mM}$ for L-serine and a $K m$ of $7.301 \pm 1.9 \mathrm{mM}$ for Lhomocysteine, indicating a high binding affinity for L-serine and a weak binding affinity for L-homocysteine. rTrC $\beta S$ was also capable of generating L-cysteine from serine and sodium sulfide, but with a very low specific activity (serine sulfhydrylase activity of $0.013 \mu \mathrm{mol} \mathrm{min} \mathrm{mg}^{-1}$ of protein). Different from T. cruzi C $\beta S$, rTrC $\beta S$ did not show any CS activity (data not shown).

\section{Total thiol content in T. rangeli and in vitro oxidative/ nitrosative stress phenotyping}

A comparative analysis of the total thiol levels of $T$. rangeli and T. cruzi revealed significant differences between these
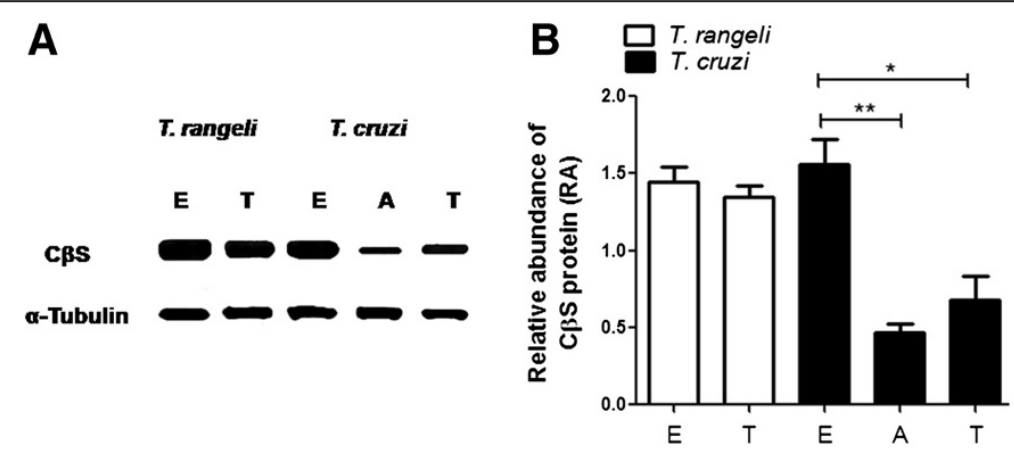

Figure 3 Protein expression levels of $C \beta S$ in $T$. rangeli and $T$. cruzi. A. Western blot analysis of soluble extracts obtained from epimastigotes (E), and trypomastigotes (T) of T. rangeli and T. cruzi, and amastigotes (A) of T. cruzi. B. Densitometric analysis of C $\beta S$ expression using ImageJ software and significant differences in C $\beta S$ expression between epimastigotes and trypomastigotes, as determined by the t-test $\left({ }^{*} \mathrm{P}<0.05\right.$, $\left.{ }^{*} \mathrm{P}<0.01\right)$. The normalisation of protein loading was performed by the immunodetection of a-tubulin. 

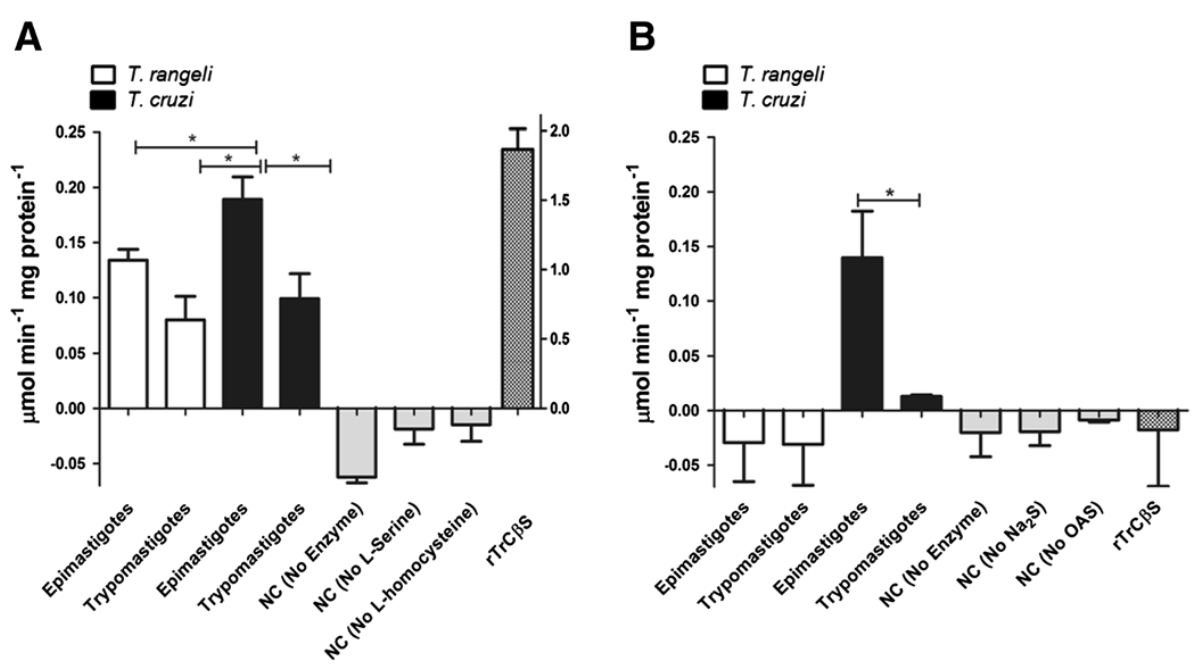

Figure 4 Detection of $C \beta S$ and CS activities in protein extracts of $T$. rangeli and $T$. cruzi epimastigotes and trypomastigotes. A. The activities of C $\beta S$ were determined in soluble extracts from trypanosomes using the recombinant enzyme rTrC $\beta S$ as a positive control (axis Z). The results represent the average of five independent experiments performed in triplicate \pm SD. B. The activities of CS were determined in soluble extracts from trypanosomes. The data represent the mean of five independent experiments performed in triplicate \pm SD. Significant difference $\left({ }^{*} P<0.05\right)$. NC = negative controls.

parasites. T. cruzi showed a thiol content of 7.8 nmoles $/ 10^{8}$ parasites, whereas $T$. rangeli had a thiol content that was almost seven times less (1.1 nmoles $/ 10^{8}$ parasites) (Figure $\left.5 \mathrm{~A}\right)$.

Based on these results, the $T$. rangeli susceptibility to oxidative and nitrosative stress was evaluated by subjecting epimastigotes to stress conditions in vitro with $\mathrm{H}_{2} \mathrm{O}_{2}$ or SNAP. This parasite was found to be more sensitive than $T$. cruzi to oxidative stress $\left(\mathrm{H}_{2} \mathrm{O}_{2}\right)$, showing an $\mathrm{IC}_{50}$ of $53 \mu \mathrm{M}$, which is significantly less $(\mathrm{P}<0.01)$ than the
$\mathrm{IC}_{50}$ obtained for $T$. cruzi epimastigotes $(188.3 \mu \mathrm{M})$. Nevertheless, the difference between these parasites was less pronounced under nitrosative stress conditions (SNAP), with $T$. rangeli being more resistant than $T$. cruzi ( $\mathrm{IC}_{50}: 312 \mu \mathrm{M}$ and $240.7 \mu \mathrm{M}$, respectively) (Figure $5 \mathrm{~B}$ ).

\section{Discussion}

Our results indicate that RTS appears to be the only pathway for cysteine biosynthesis in $T$. rangeli. At the
A
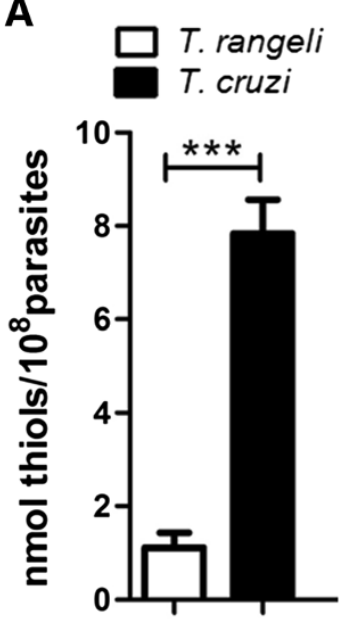

B

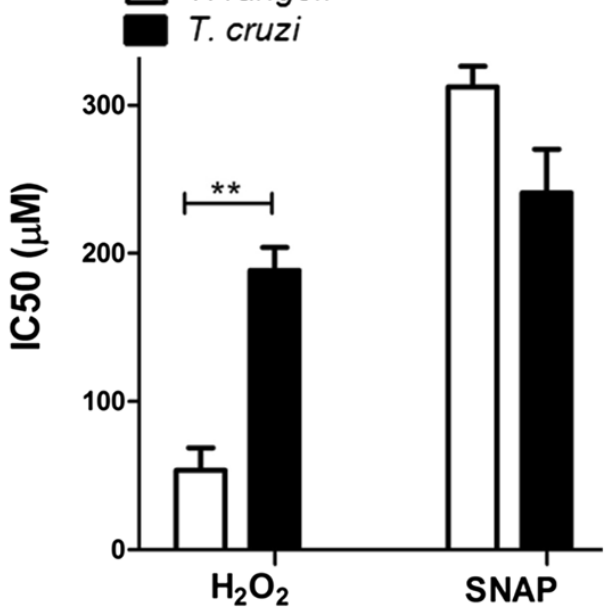

Figure 5 Total thiol content and effects of oxidative and nitrosative stress on $T$. rangeli and $T$. cruzi viability. A. The total thiol content was determined in soluble extracts obtained from the epimastigote form. Error bars represent the SEM of three independent experiments. B. In vitro susceptibility of epimastigotes of $\mathrm{T}$. rangeli and $\mathrm{T}$. cruzi exposed to oxidative stress by hydrogen peroxide $\left(\mathrm{H}_{2} \mathrm{O}_{2}\right)$ or nitrosative stress by S-nitroso-N-acetylpenicillamine (SNAP). Error bars represent the SEM of three independent experiments, performed in quadruplicate. Significant differences were detected by a one-way ANOVA, followed by Bonferroni post-tests (**P $<0.01$, ${ }^{* * * P}<0.001$ ). 
genomic level, $T$. rangeli contains single copies of genes coding for the CBS and CGL (cystathionine $\gamma$-lyase) enzymes of the RTS pathway but lacks genes encoding a protein of the cysteine de novo biosynthetic pathway (SAT). Additionally, a partial gene sequence for CS was found that has an A-G nucleotide transition at position 470, which generates a stop codon (TAG) (data not shown); thus, the truncated protein encoded lacks two of the four lysine residues required for CS activity.

A biochemical analysis of $\mathrm{rTrC} \beta \mathrm{S}$ showed a higher $\mathrm{C} \beta \mathrm{S}$ activity compared to hsC $\beta \mathrm{S}$ for generating cystathionine via the condensation of L-serine and L-homocysteine, though $\mathrm{rTrC} \beta \mathrm{S}$ is less active than TcC $\beta S$ [32-34]. In spite of this, the binding substrate affinity was comparable to the affinity of the C $\beta S$ enzyme from $L$. major and humans [9]. Similar to other C $\beta S$ s, rTrC $\beta S$ can also form cysteine from L-serine and sodium sulfide, but is unable to utilise OAS and sulfide to catalyse the production of cysteine. Nevertheless, inter-species variations in other C $\beta S$ catalysed reactions [24] could explain the absence of CS activity mediated by $\operatorname{TrC} \beta S$.

The presence of a truncated CS gene as revealed by high-quality sequencing (Phred $\geq 50$ ), and the absence of CS activity in both epimastigote and trypomastigote extracts suggests that the de novo cysteine biosynthetic pathway is absent or not functional in T. rangeli. Nevertheless, $T$. rangeli possesses a functional RTS pathway, a characteristic shared with $T$. brucei, for which only C $\beta S$ activity has been reported in bloodstream trypomastigote extracts but at a very low level [35]. This result indicates that similarities in the metabolism of sulfur-containing amino acids exist between $T$. rangeli and $T$. brucei, another parasite that does not possess an intracellular mammalian host stage. Such findings may suggest that the extracellular stage of the life cycle of parasitic protozoa and the RTS biosynthetic pathway are causally connected.

No stage-specific association was found for T. rangeli C $\beta S$ activity and protein levels, contrasting with T. cruzi, with epimastigotes (insect-form) that present significantly higher activity and protein levels. Other studies on the RTS pathway in T. cruzi have demonstrated the same stage-specific regulation of this pathway and have shown a likely association with the complex life cycle of this parasite and the availability of sulfur-containing amino acids in different parasite environments [33,34].

We found significantly lower levels of total thiol content in $T$. rangeli compared to $T$. cruzi epimastigotes. Based on the fact that cysteine forms the basic building block of all thiol antioxidants [2], one possible explanation for the lowest thiol levels observed may be because $T$. rangeli only uses the RTS pathway as a cysteine biosynthesis source. Another important aspect is related to the fact that exogenous organic sulfur-containing amino acids can be supplied by transporters $[3,9,36]$. However, such a mechanism and its possible influence on the total thiol levels in $T$. rangeli remain to be explored.

Different from $T$. cruzi, which faces oxidative stress in the mammalian host and within the triatomine vector's digestive tract, $T$. rangeli is exposed to further oxidative and nitrosative stress while reaching the triatomine hemolymph and salivary glands [37]. Recently, studies have demonstrated the activation of the vector immune system during $T$. rangeli-Rhodnius prolixus interactions, including the generation of nitric oxide and superoxide free radicals [38-40]. The greater resistance of $T$. rangeli to SNAP compared to T. cruzi could be explained by the ability of $T$. rangeli to modulate insect immune/cellular factors $[38,41]$, especially those related to nitrosative production, thus allowing the parasite to survive and multiply freely in the insect's hemolymph and to invade and complete its development within the salivary glands [42].

Because thiols have been demonstrated to be the central metabolites in the redox metabolism of several parasite species [43], thus playing an important role in protection against oxidative stress, the higher $T$. rangeli susceptibility to hydrogen peroxide may be due its reduced total thiol content. In addition, the absence of an active CS enzyme potentiates the $T$. rangeli susceptibility to hydrogen peroxide, leading to the death of the parasite. Such findings are in agreement with reports in amoebae, whereby the overexpression of CS increases the total cellular thiol content and the resistance to oxidative stress due to hydrogen peroxide [8].

\section{Conclusion}

These findings demonstrate that the RTS pathway is active in $T$. rangeli, suggesting that this may be the only pathway for cysteine biosynthesis in this parasite because no CS activity was detected in epimastigotes and trypomastigotes and the CS genes are truncated due to the presence of stop codons. In this sense, the RTS pathway would have an important functional role during the insect stage of the life cycle of this protozoan parasite.

\section{Competing interests}

The authors declare that they have no competing interests.

\section{Authors' contributions}

IR and JT participated in the conception and design of the study and wrote the manuscript. LY was involved in cloning C $B S$. MS, AR, and EG were involved in the conception of the study and wrote the manuscript. All authors read and approved the final version of the manuscript.

\section{Acknowledgements}

$I R$, JT, and LY are recipients of CAPES or CNPq/PIBIC scholarships. This work was supported by CAPES, FINEP, and CNPq - Brazilian Government Agencies. The funders had no role in the study design, data generation and analysis, decision to publish, or preparation of the manuscript. The authors thank Dr Concepción Judith Puerta (Pontificia Universidad Javeriana, Bogota, Colombia) for critical reading and suggestions on the manuscript. We thank Aline Daiane Schlindwein, MSc for technical assistance in C $\beta S$ and CS sequencing. IR and JT give a special acknowledgment in memory of John Walker, our friend and colleague. 
Author details

${ }^{1}$ Laboratórios de Protozoologia e de Bioinformática, Departamento de Microbiologia, Imunologia e Parasitologia, Centro de Ciências Biológicas, Universidade Federal de Santa Catarina, Florianópolis, SC 88040-970, Brasil.

${ }^{2}$ Centro de Pesquisas René Rachou, Fiocruz, Belo Horizonte, MG, Brasil.

Received: 19 December 2013 Accepted: 15 April 2014

Published: 24 April 2014

\section{References}

1. Nozaki T, Ali V, Tokoro M: Sulfur-containing amino acid metabolism in parasitic protozoa. Adv Parasitol 2005, 60:1-99.

2. Krauth-Siegel RL, Leroux AE: Low-molecular-mass antioxidants in parasites. Antioxid Redox Signal 2012, 17(4):583-607.

3. Canepa GE, Bouvier LA, Miranda MR, Uttaro AD, Pereira CA Characterization of Trypanosoma cruzi L-cysteine transport mechanisms and their adaptive regulation. FEMS Microbiol Lett 2009, 292(1):27-32.

4. Beinert $\mathrm{H}, \mathrm{Holm} \mathrm{RH}$, Münck E: Iron-sulfur clusters: nature's modular, multipurpose structures. Science 1997, 277(5326):653-659.

5. Thomas D, Surdin-Kerjan Y: Metabolism of sulfur amino acids in Saccharomyces cerevisiae. Microbiol Mol Biol Rev 1997, 61(4):503-532.

6. Aitken SM, Kirsch JF: The enzymology of cystathionine biosynthesis: strategies for the control of substrate and reaction specificity. Arch Biochem Biophys 2005, 433(1):166-175.

7. Feldman-Salit A, Wirtz M, Hell R, Wade RC: A mechanistic model of the cysteine synthase complex. J Mol Biol 2009, 386(1):37-59.

8. Nozaki T, Asai T, Sanchez LB, Kobayashi S, Nakazawa M, Takeuchi T: Characterization of the gene encoding serine acetyltransferase, a regulated enzyme of cysteine biosynthesis from the protist parasites Entamoeba histolytica and Entamoeba dispar. Regulation and possible function of the cysteine biosynthetic pathway in Entamoeba. J Biol Chem 1999, 274(45):32445-32452

9. Williams RA, Westrop GD, Coombs GH: Two pathways for cysteine biosynthesis in Leishmania major. Biochem J 2009, 420(3):451-462.

10. Raj I, Kumar S, Gourinath S: The narrow active-site cleft of O-acetylserine sulfhydrylase from Leishmania donovani allows complex formation with serine acetyltransferases with a range of C-terminal sequences. Acta Crystallogr D Biol Crystallogr 2012, 68(Pt 8):909-919.

11. Venter JC, Adams MD, Myers EW, Li PW, Mural RJ, Sutton GG, Smith HO, Yandell M, Evans CA, Holt RA, Gocayne JD, Amanatides P, Ballew RM, Huson DH, Wortman JR, Zhang Q, Kodira CD, Zheng XH, Chen L, Skupski M, Subramanian G, Thomas PD, Zhang J, Gabor Miklos GL, Nelson C, Broder S, Clark AG, Nadeau J, McKusick VA, Zinder N, et al: The sequence of the human genome. Science 2001, 291(5507):1304-1351.

12. Wirtz M, Berkowitz O, Droux M, Hell R: The cysteine synthase complex from plants. Mitochondrial serine acetyltransferase from Arabidopsis thaliana carries a bifunctional domain for catalysis and protein-protein interaction. Eur J Biochem 2001, 268(3):686-693.

13. Thomson L, Denicola A, Radi R: The trypanothione-thiol system in Trypanosoma cruzi as a key antioxidant mechanism against peroxynitrite-mediated cytotoxicity. Arch Biochem Biophys 2003, 412(1):55-64.

14. Piacenza L, Zago MP, Peluffo G, Alvarez MN, Basombrio MA, Radi R: Enzymes of the antioxidant network as novel determiners of Trypanosoma cruzi virulence. Int J Parasitol 2009, 39(13):1455-1464.

15. D'Alessandro A, Saraiva N: Trypanosoma rangeli. In Parasitic Protozoa, Volume 2. 2nd edition. Edited by Kreirer JP BJ. San Diego: Academic Press; 1992:1-54

16. Camargo EP: Growth and differentiation in Trypanosoma cruzi I. Origin of metacyclic trypanosomes in liquid media. Rev Inst Med Trop Sao Paulo 1964, 6:93-100.

17. Koerich LB, Emmanuelle-Machado P, Santos K, Grisard EC, Steindel M: Differentiation of Trypanosoma rangeli: high production of infective Trypomastigote forms in vitro. Parasitol Res 2002, 88(1):21-25.

18. Pinto AM, Sales PC, Camargos ER, Silva AM: Tumour necrosis factor (TNF)-mediated NF-KB activation facilitates cellular invasion of non-professional phagocytic epithelial cell lines by Trypanosoma cruzi. Cell Microbiol 2011, 13:1518-1529.

19. Grisard EC, Stoco PH, Wagner G, Sincero TC, Rotava G, Rodrigues JB, Snoeijer CQ, Koerich LB, Sperandio MM, Bayer-Santos E, Fragoso SP, Goldenberg S, Triana O, Vallejo GA, Tyler KM, Dávila AM, Steindel M:
Transcriptomic analyses of the avirulent protozoan parasite Trypanosoma rangeli. Mol Biochem Parasitol 2010, 174(1):18-25.

20. Sambrook J, Russell DW: Molecular Cloning : a Laboratory Manual. 3rd edition. Cold Spring Harbor, N.Y.: Cold Spring Harbor Laboratory Press; 2001.

21. Ewing B, Hillier L, Wendl MC, Green P: Base-calling of automated sequencer traces using phred. I. Accuracy assessment. Genome Res 1998, 8(3):175-185.

22. Decuypere S, Vanaerschot M, Brunker K, Imamura H, Müller S, Khanal B, Rijal $\mathrm{S}$, Dujardin JC, Coombs GH: Molecular mechanisms of drug resistance in natural Leishmania populations vary with genetic background. PLOS Negl Trop Dis 2012, 6(2):e1514

23. Gallagher S, Winston SE, Fuller SA, Hurrell JG: Immunoblotting and immunodetection. Curr Protoc Mol Biol 2008, Chapter 10: Unit 10.18: 10.8.1-10.8.28

24. Walker J, Barrett J: Cystathionine beta-synthase and gamma-cystathionase in helminths. Parasitol Res 1991, 77(8):709-713.

25. Kashiwamata S, Greenberg DM: Studies on cystathionine synthase of rat liver. Properties of the highly purified enzyme. Biochim Biophys Acta 1970, 212(3):488-500.

26. Gaitonde MK: A spectrophotometric method for the direct determination of cysteine in the presence of other naturally occurring amino acids. Biochem J 1967, 104(2):627-633.

27. Droux M, Martin J, Sajus P, Douce R: Purification and characterization of O-acetylserine (thiol) lyase from spinach chloroplasts. Arch Biochem Biophys 1992, 295(2):379-390.

28. Mukhopadhyay R, Dey S, Xu N, Gage D, Lightbody J, Ouellette M, Rosen BP: Trypanothione overproduction and resistance to antimonials and arsenicals in Leishmania. Proc Natl Acad Sci U S A 1996, 93(19):10383-10387.

29. Ellman GL: Tissue sulfhydryl groups. Arch Biochem Biophys 1959, 82(1):70-77.

30. Räz B, Iten M, Grether-Bühler Y, Kaminsky R, Brun R: The Alamar Blue assay to determine drug sensitivity of African trypanosomes (T.b. rhodesiense and T.b. gambiense) in vitro. Acta Trop 1997, 68(2):139-147.

31. Kelly JM, Taylor MC, Smith K, Hunter KJ, Fairlamb AH: Phenotype of recombinant Leishmania donovani and Trypanosoma cruzi which overexpress trypanothione reductase. Sensitivity towards agents that are thought to induce oxidative stress. Eur J Biochem 1993, 218(1):29-37.

32. Taoka S, Widjaja L, Banerjee R: Assignment of enzymatic functions to specific regions of the PLP-dependent heme protein cystathionine beta-synthase. Biochemistry 1999, 38(40):13155-13161.

33. Nozaki T, Shigeta Y, Saito-Nakano Y, Imada M, Kruger WD: Characterization of transsulfuration and cysteine biosynthetic pathways in the protozoan hemoflagellate, Trypanosoma cruzi. Isolation and molecular characterization of cystathionine beta-synthase and serine acetyltransferase from Trypanosoma. J Biol Chem 2001, 276(9):6516-6523.

34. Marciano D, Santana M, Nowicki C: Functional characterization of enzymes involved in cysteine biosynthesis and $\mathrm{H}(2) \mathrm{S}$ production in Trypanosoma cruzi. Mol Biochem Parasitol 2012, 185(2):114-120.

35. Yarlett N, Bacchi CJ: Effect of DL-alpha-difluoromethylornithine on methionine cycle intermediates in Trypanosoma brucei brucei. Mol Biochem Parasitol 1988, 27(1):1-10.

36. Duszenko M, Ferguson MA, Lamont GS, Rifkin MR, Cross GA: Cysteine eliminates the feeder cell requirement for cultivation of Trypanosoma brucei bloodstream forms in vitro. J Exp Med 1985, 162(4):1256-1263.

37. Azambuja P, Ratcliffe NA, Garcia ES: Towards an understanding of the interactions of Trypanosoma cruzi and Trypanosoma rangeli within the reduviid insect host Rhodnius prolixus. An Acad Bras Cienc 2005, 77(3):397-404.

38. Whitten MM, Mello CB, Gomes SA, Nigam Y, Azambuja P, Garcia ES, Ratcliffe NA: Role of superoxide and reactive nitrogen intermediates in Rhodnius prolixus (Reduviidae)/Trypanosoma rangeli interactions. Exp Parasitol 2001, 98(1):44-57.

39. Whitten M, Sun F, Tew I, Schaub G, Soukou C, Nappi A, Ratcliffe N: Differential modulation of Rhodnius prolixus nitric oxide activities following challenge with Trypanosoma rangeli, T. cruzi and bacterial cell wall components. Insect Biochem Mol Biol 2007, 37(5):440-452.

40. Garcia ES, Castro DP, Figueiredo MB, Genta FA, Azambuja P: Trypanosoma rangeli: a new perspective for studying the modulation of immune reactions of Rhodnius prolixus. Parasit Vectors 2009, 2(1):33.

41. Gazos-Lopes F, Mesquita RD, Silva-Cardoso L, Senna R, Silveira AB, Jablonka W, Cudischevitch CO, Carneiro AB, Machado EA, Lima LG, Monteiro RQ, Nussenzveig $\mathrm{RH}$, Folly E, Romeiro A, Vanbeselaere J, Mendonça-Previato L, Previato JO, Valenzuela JG, Ribeiro JM, Atella GC, Silva-Neto MA: Glycoinositolphospholipids from Trypanosomatids subvert nitric oxide production in Rhodnius prolixus salivary glands. PLoS One 2012, 7(10):e47285. 
42. Garcia ES, Castro DP, Figueiredo MB, Azambuja P: Parasite-mediated interactions within the insect vector: trypanosoma rangeli strategies. Parasit Vectors 2012, 5:105.

43. Krauth-Siegel RL, Comini MA: Redox control in trypanosomatids, parasitic protozoa with trypanothione-based thiol metabolism. Biochim Biophys Acta 2008, 1780(11):1236-1248.

doi:10.1186/1756-3305-7-197

Cite this article as: Romero et al.: Transsulfuration is an active pathway for cysteine biosynthesis in Trypanosoma rangeli. Parasites \& Vectors 2014 7:197.

\section{Submit your next manuscript to BioMed Central and take full advantage of:}

- Convenient online submission

- Thorough peer review

- No space constraints or color figure charges

- Immediate publication on acceptance

- Inclusion in PubMed, CAS, Scopus and Google Scholar

- Research which is freely available for redistribution 